\title{
Olfactory Performance among Hospital Residents
}

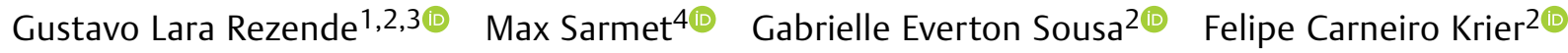 \\ Diderot Rodrigues Parreira2 ${ }^{20}$ Selma Aparecida Kuckelhaus ${ }^{30}$
}

1 Otorhinolaryngology Departament, Hospital de Base do Distrito

Address for correspondence Gustavo Lara Rezende, MD, PhD, SEPS

Federal (HBDF), Brasília, DF, Brazil

709/909, CMJA, sala 223 A, Brasília, DF, 70390-095, Brazil

${ }^{2}$ Faculdade de Medicina, Universidade Católica de Brasília (UCB), (e-mail: glararezende@gmail.com).

Taguatinga, Brasília, DF, Brazil

${ }_{3}$ Morphology Departament, Faculdade de Medicina, Universidade de

Brasília (UnB), Brasília, DF, Brazil

${ }^{4}$ Hospital de Apoio de Brasília (HAB), Brasília, DF, Brazil

Int Arch Otorhinolaryngol 2022;26(1):e32-e37.

\begin{abstract}
Keywords

- olfactory test

- dysosmia

- residents

- health workers

Introduction Smell plays an important role in the maintenance of health and quality of life of the general population. Health workers with olfactory impairment may not be able to help diagnose certain diseases, and subsequently increase the risk of hazardous events and mortality among those affected. 'Odor learning' requires repeated experiences with different smells to develop a discriminatory ability, and this is a process that takes years. Because of that, physicians of certain medical specialities have better odor detection than others.

Objective To study the olfactory performance and associated factors of otorhinolaryngology residents compared with residents of different medical specialities in a representative sample of a tertiary hospital.

Methods The University of Pennsylvania Smell Identification Test (UPSIT) was used to compare olfactory performance. Clinical and epidemiological data were collected among 42 hospital residents.

Results Otorhinolaryngology residents presented an average UPSIT score of 35.0, and the other residents, a score of $32.8(p=0.02)$ Of all the residents, $40.5 \%$ showed some grade of olfactory impairment. Half of the females students in the first year of residency showed olfactory dysfunction. The multivariate analyses found age $(p=0.03 ; 95 \%$ confidence interval for $\beta=0.33$ ) to be an independent predictor of the UPSIT score. Conclusion The present study demonstrated that otorhinolaryngology residents have greater olfactory capacity compared with other residents. Future studies should explore the relevant factors of olfactory impairment and its impact on quality of life in this population.
\end{abstract}

\section{Introduction}

Smell plays an important role in the maintenance of health and quality of life of the general population. Health workers with olfactory impairment may not be able to help diagnose

received

July 5,2020

accepted

September 27, 2020

published online

February 19, 2021

February 19.2021

DOI https://doi.org/ $10.1055 / \mathrm{s}-0040-1719122$. ISSN 1809-9777. certain diseases, ${ }^{1-3}$ and subsequently increase the risk of hazardous events and mortality among those affected. ${ }^{4}$

Little research has been conducted on the prevalence of olfactory disorders among health workers due to the

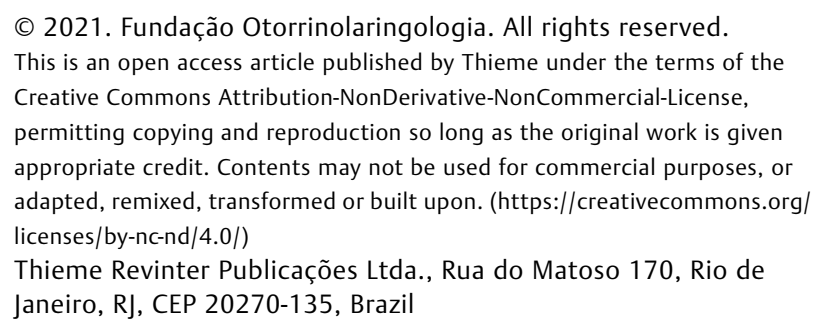


difficulty of standardising tests and their costs. Cross-sectional studies have demonstrated the prevalence of olfactory disorders in $\sim 19 \%$ of individuals in the general population. ${ }^{5}$ Among health professionals, there is still no data on the use of this essential work tool during the physical examination of patients and its important role in detecting diseases. ${ }^{6}$ 'Odor learning' requires repeated experiences with different smells to develop a discriminatory ability, and this is a process that takes years. ${ }^{4}$ Because of that, physicians of certain medical specialities would be able to have better odor detection than others.

In addition to the importance of smell for health professionals in the diagnosis of diseases in general, the determination of the olfaction status is an important tool of occupational medicine and public health planning. ${ }^{7}$ The present study employed a highly reliable and standardized 40 -item odor identification test ${ }^{8}$ to study the olfactory performance and associated factors of otorhinolaryngology residents compared with residents of different medical specialities in a representative sample of a tertiary hospital.

\section{Methods}

\section{Subject Enrollment}

The study was performed with subjects who were recruited at a tertiary hospital to test their olfactory capacity using the University of Pennsylvania Smell Identification Test (UPSIT) (-Fig. 1). All subjects attended a residency program. The following epidemiological data were collected: age, sex, ethnic group, monthly household income, presence of nasal diseases, presence of rhinitis, smoking behavior, continuous use of medications, and comorbidities.

Individuals with an acute respiratory infection or a history of head trauma were excluded to avoid participants with odor impairment secondary to other etiologies. The initial study population consisted of 50 subjects. Residents from all units of the hospital were invited to participate voluntarily. The present study was approved by the institutional Ethics Committee for Analysis of Research Projects of the Clinical Board.

\section{Residency Programs}

The individuals were divided into two groups according to the specialty of the residency program: otorhinolaryngology or other specialties. They were also divided into groups according to the year of residency ( $R 1=$ first year in the program; $\mathrm{R} 2$ = second year in the program etc.) and type of residency program (clinical or surgical).

\section{Monthly Household Income}

We also divided the residents into four income-based groups, analogous to the categories previously used in Fornazieri et al., ${ }^{9}$ which were based on the Brazilian classification of socioeconomic classes.

\section{Ethnicity}

Ethnicity was classified according to the definitions of the Brazilian Institute of Geography and Statistics (Instituto Brasileiro de Geografia e Estatística, IBGE, in the Portuguese acronym). ${ }^{9}$ The subjects of the present study were selfdefined as White, Black, and mixed-race Brazilians.

\section{Olfactory Evaluation}

All participants completed the UPSIT, a widely used forcedchoice standardized test of olfactory function. ${ }^{8}$ This test consisted of four booklets of ten odorants each. The stimuli were embedded into microcapsules present in brown strips at the bottom of each page. The examiner directed the subjects to scrape the strip with a pencil, which released the odorant. The subjects then answered a multiple-choice question to describe the smell as they perceived it. Based on the test scores, each subject's olfactory function could be

\section{TERTIARY HOSPITAL}
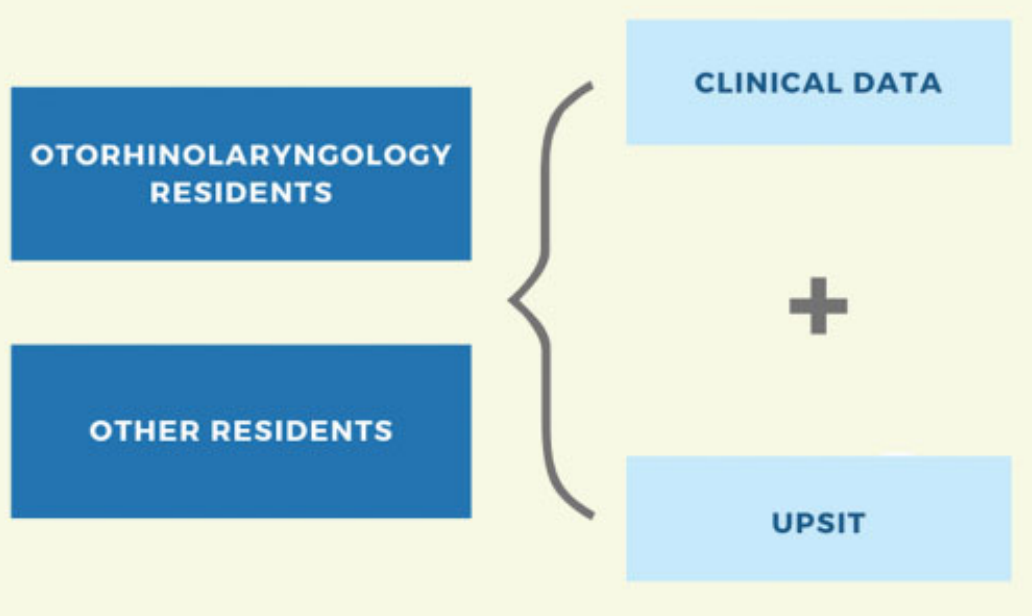

Fig. 1 Key elements of the study. 
classified into the normosmia, microsmia (mild, moderate, and severe), and anosmia categories. The scores ranged from 0 to 40. The UPSIT was originally developed for North American English-speaking groups, but it has since been modified for other cultures and translated into several other languages. The Brazilian-Portuguese version of the scale was used in the present study. This version was developed through a series of experiments to adapt the test to Brazilian populations. $^{9}$

\section{Statistical Analysis}

Data were analyzed using the Statistical Package for the Social Sciences (SPSS, IBM Corp., Armonk, NY, US) software, version 24. Descriptive statistics were performed using epidemiological data. The UPSIT scores were compared among the groups using a two-sample $t$-test for the parametric analyses and the Wilcoxon-Mann-Whitney test for the non-parametric analyses. The relationships among the variables were assessed using the Pearson correlation. The Chi-squared test was used to assess the associations among frequencies within the categorical variables. A series of hierarchical multiple linear regressions was used to study the independent influence of the years of residency on the UPSIT score. The same analysis was performed using the following variables: age, ethnicity, presence of comorbidities, and smoking status.

\section{Quality Assessment}

A Strengthening the Reporting of Observational Studies in Epidemiology (STROBE) checklist of cross-sectional studies ${ }^{10}$ was used as a guide to ensure the quality of the data presentation.

\section{Results}

\section{Study Population and Demographics}

Out of 50 potential subjects, 42 were included in the study. A total of eight subjects were excluded because they had acute respiratory infections. Out of all the included subjects, $47.6 \%$ were male $(n=20)$, and $52.4 \%$ were female $(n=22)$ (-Table 1). The median age of the subjects was 27 years (range: 23 to 35 years). With regard to monthly household income, $38.1 \%(n=16)$ were in Class B, and $61.9 \%(n=26)$ were in Class A. Regarding ethnicity, $73.8 \%$ of the subjects were self-defined as White Brazilian $(n=31), 2.4 \%$, as Black Brazilian $(n=1)$, and $23.8 \%$, as mixed-race Brazilian $(n=10)$. The UPSIT results were correlated with age $(r=0.33$; $p=0.03)$ and the number of continuous-use medications $(r=0.35 ; p=0.02)$, but not with monthly household income.

\section{Residency Programs}

There was an equal number of subjects in the 2 residency groups (otorhinolaryngology residents: $n=21$; other residents: $n=21$ ). The group of other residents consisted of residents of: anaesthesiology $(19.0 \%, n=4)$, infectology (4.8\%, $n=1)$, gastroenterology $(4.8 \%, n=1)$, medical clinic (9.5\%, $n=2)$, nephrology $(14.3 \%, n=3)$, neurology $(4.8 \%$, $n=1)$, neurosurgery $(4.8 \%, n=1)$, oral and maxillofacial surgery $(4.8 \%, n=1)$, physiatry $(9.5 \%, n=2)$, and physical therapy $(23.8 \%, n=5)$. The residents were also divided into either a surgical $(64.3 \%, n=27)$ or clinical $(35.7 \%, n=15)$ group.

\section{Comorbidities and Medication Use}

Regarding comorbidities, $16.7 \%(n=7)$ reported having a disease or condition. The most common diseases and conditions were hypothyroidism and asthma, but attention deficit hyperactivity disorder, melanoma, and shoulder dislocation were also reported. With regard to nasal diseases and conditions, 40.5\% reported a previous diagnosis of nasal disease $(n=17)$, and, out of this group, $26.2 \%(n=11)$ specifically reported rhinitis (-Table 1). In total, $40 \%$ of the participants reported continuous use of medications ( $n=17$ ). Considering the whole sample, we observed mainly the continuous use of contraceptives (26.8\%, $n=11)$ and antidepressants $(11.9 \%, n=5)$ (venlafaxine, desvenlafaxine, escitalopram). A minority of subjects reported continuous use of topical corticosteroids (budesonide, mometasone, fluticasone), attention deficit hyperactivity disorder

Table 1 Demographic and clinical characteristics of the study population

\begin{tabular}{|l|l|l|l|}
\hline & Otorhinolaryngology residents & Other residents & $p$-value \\
\hline $\mathrm{N}$ & 21 & 21 & $27.7 \pm 2.7$ \\
\hline Age (years) & $27.9 \pm 2.5$ & $32.8 \pm 3.9$ & $0.70^{\mathrm{a}}$ \\
\hline $\begin{array}{l}\text { University of Pennsylvania Smell } \\
\text { Identification Test (UPSIT) score }\end{array}$ & $35.0 \pm 2.5$ & $11(52.4)$ & $0.02^{\mathrm{a}}$ \\
\hline Gender no. female (\%) & $11(52.4)$ & 14.3 & $1.00^{\mathrm{b}}$ \\
\hline Comorbidity (\%) & 19.0 & 0 & $0.68^{\mathrm{b}}$ \\
\hline $\begin{array}{l}\text { Number of chronic use medication per } \\
\text { individual, median }\end{array}$ & 1 & 42.9 & $0.25^{\mathrm{a}}$ \\
\hline Nasal disease (\%) & 38.1 & 33.3 & $0.75^{\mathrm{b}}$ \\
\hline Rhinitis (\%) & 19.0 & 33.3 & $0.33^{\mathrm{b}}$ \\
\hline Continuous use of medication (\%) & 52.4 & 19.0 & $0.36^{\mathrm{b}}$ \\
\hline Smoking (\%) & 4.8 & $0.15^{\mathrm{b}}$ \\
\hline
\end{tabular}

Notes: ${ }^{\mathrm{a} T w o-s a m p l e ~ t-t e s t ;}{ }^{\mathrm{b}} \mathrm{Chi}$-squared test. 
Table 2 University of Pennsylvania Smell Identification Test (UPSIT) scores regarding residency

\begin{tabular}{|c|c|c|c|c|c|c|c|c|}
\hline Variables & $\mathrm{N}$ & Age* $^{*}$ & UPSIT score* & Standard deviation & Median & Minimum & Maximum & $p$-value \\
\hline \multicolumn{8}{|l|}{ Residency program } & \multirow[t]{3}{*}{$0.02^{\mathrm{a}}$} \\
\hline Otorhinolaryngology & 21 & 28 & 35.0 & 2.5 & 35 & 29 & 40 & \\
\hline Others & 21 & 27 & 32.8 & 3.9 & 34 & 26 & 39 & \\
\hline \multicolumn{8}{|l|}{ Year of residency } & \multirow[t]{5}{*}{$0.72^{\mathrm{b}}$} \\
\hline R1 & 18 & 27 & 33.8 & 3.7 & 34 & 26 & 40 & \\
\hline R2 & 13 & 28 & 33.3 & 3.5 & 34 & 27 & 38 & \\
\hline R3 & 10 & 29 & 34.9 & 3.2 & 35 & 27 & 39 & \\
\hline R4 & 1 & 28 & 34.0 & - & - & - & - & \\
\hline \multicolumn{8}{|l|}{ Residency type } & $0.23^{\mathrm{b}}$ \\
\hline Clinical & 15 & 27 & 32.8 & 4.2 & 34 & 26 & 39 & \\
\hline Surgical & 27 & 28 & 34.5 & 2.8 & 35 & 29 & 40 & \\
\hline
\end{tabular}

Notes: *average; ${ }^{a}$ two-sample $t$-test for the UPSIT scores; ${ }^{b}$ Wilcoxon-Mann-Whitney test for the UPSIT scores.

drugs (methylphenidate and lisdexamfetamine), thyroid drugs (levothyroxine), systemic corticosteroids (prednisone), and pain medication (trometamol). There was no statistically significant difference in the UPSIT scores regarding the type of drug.

\section{Olfactory Evaluation}

With regard to olfactory function, $59.5 \%$ of the sample had normosmia, and $40.5 \%$ showed some grade of olfactory impairment. We observed no cases of severe microsmia or anosmia. The median overall UPSIT score was of 35 (range: 26$40)$. The otorhinolaryngology residents presented an average UPSIT score of 35.0, and the other residents, of $32.8(p=0.02)$ (-Table 2). The UPSIT scores according to the residency program, type and year of residency are presented in -Table 2, and, according to the demographics, in - Table 3. The UPSIT results were not found to be correlated with year of residency $(\mathrm{r}=0.86 ; p=0.58)$. - Table 4 shows the values and associations between olfactory function and gender, specialty of the residency program, and year of residency. We found no differences in UPSIT results between groups in terms of gender, ethnicity, household income, specialty of the residency program, year of residency, comorbidities, presence of nasal diseases, presence of rhinitis, and smoking status. The multivariate analyses found age $(r=0.32, p=0.03 ; 95 \%$ confidence interval for $\beta=0.33$ ) to be an independent predictor of the UPSIT score.

\section{Discussion}

The results of the 40-item olfaction identification test demonstrated that otorhinolaryngology residents have greater olfactory capacity compared with residents of other specialities. Although small differences in the UPSIT scores were observed between these two groups (35.0 versus 32.8, $p=0.02$ ), they were clinically significant. According to the UPSIT Administration Manual, normosmia is defined when UPSIT scores range from 34 to 40 points (males) and 35 to 40 points (females). Mild microsmia ranged from 30 to 33 points (males) and from 31 to
34 points (females). Thus, the average UPSIT score of otorhinolaryngology residents was classified as normosmia, whereas the other group had mild microsmia. ${ }^{8}$

We believe that the awareness of otorhinolaryngology residents regarding the prevention of nasal inflammatory and infectious processes should be associated with these results. ${ }^{11,12}$ In addition, we believe that easy access to free samples of topical nasal corticosteroids and the common practice of washing the nose with saline solution were significant factors that subjects forgot to mention during the interview. These factors would have prevented any inflammatory disease of the olfactory epithelium ${ }^{12}$ and the common epistaxis caused by the dry climate of our geographic area. ${ }^{13}$ Moreover, these factors can also be considered as specific and involuntary olfactory training, which models the use of smell among wine and coffee experts. ${ }^{14}$ Future studies that examine the role of individual practices and training in the prevention of olfaction disorders should be performed.

With regard to gender, in our sample, women had better olfactory performance than men (34.2 versus 33.6 respectively). It is well known that, among the general population, women have greater olfactory and gustatory sensitivity than men, ${ }^{15,16}$ and, in a recent meta-analysis ${ }^{17}$ that assessed the effect of gender on odor identification, a superior performance was observed among women, but only among adults between 18 and 50 years of age. However, we observed a greater prevalence of dysosmia among females than among males ( $50 \%$ versus $30 \%$ respectively). The literature shows that the complaint of dysosmia is more frequent in women than in men. ${ }^{15}$

The percentage of smokers in the otorhinolaryngology group was much lower (4.8\%) than that of the other group (19\%). Although the differences in the UPSIT scores between smokers and non-smokers were not statistically significant $(p=0.67)$, we believe that this environmental factor could result in lower UPSIT scores, according to the available medical literature. ${ }^{8,9}$ Only $11.9 \%$ of our sample were smokers, but, unfortunately, we did not control the tobacco load of the participants.

In a previous study ${ }^{18}$ on the cross-cultural adaptation of the UPSIT for use in the Brazilian population $(n=49$; mean 
Table 3 University of Pennsylvania Smell Identification Test (UPSIT) scores according to demographics

\begin{tabular}{|c|c|c|c|c|c|c|c|}
\hline Variables & $\mathrm{N}$ & Mean score & Standard deviation & Median & Minimum & Maximum & $p$-value \\
\hline Entire sample & 42 & 33.9 & 3.4 & 35 & 26 & 40 & - \\
\hline \multicolumn{7}{|l|}{ Gender } & $0.54^{a}$ \\
\hline Male & 20 & 33.6 & 3.5 & 35 & 26 & 39 & \\
\hline Female & 22 & 34.2 & 3.5 & & 27 & 40 & \\
\hline \multicolumn{7}{|l|}{ Ethnicity } & $0.76^{\mathrm{b}}$ \\
\hline White Brazilian & 31 & 34.1 & 3.3 & 35 & 27 & 39 & \\
\hline Black Brazilian & 1 & - & - & - & - & - & \\
\hline Mixed Brazilian & 10 & 33.2 & 4.2 & 34 & 26 & 40 & \\
\hline \multicolumn{7}{|c|}{ Monthly household income } & $0.80^{\mathrm{b}}$ \\
\hline Group 3 & 16 & 33.9 & 2.7 & 34 & 29 & 38 & \\
\hline Group 4 & 26 & 33.9 & 3.9 & 35 & 26 & 40 & \\
\hline \multicolumn{7}{|l|}{ Comorbidity } & $0.46^{\mathrm{b}}$ \\
\hline Yes & 7 & 34.5 & 4.0 & 35 & 29 & 39 & \\
\hline No & 35 & 33.8 & 3.4 & 34 & 26 & 40 & \\
\hline \multicolumn{7}{|l|}{ Nasal disease } & $0.43^{b}$ \\
\hline Yes & 17 & 34.3 & 3.5 & 35 & 27 & 39 & \\
\hline No & 25 & 33.6 & 3.5 & 34 & 26 & 40 & \\
\hline \multicolumn{7}{|l|}{ Rhinitis } & $0.26^{\mathrm{b}}$ \\
\hline Yes & 11 & 33.0 & 3.6 & 34 & 27 & 39 & \\
\hline No & 31 & 34.2 & 3.4 & 35 & 26 & 40 & \\
\hline \multicolumn{7}{|l|}{ Smoking } & $0.67^{b}$ \\
\hline Yes & 5 & 34.6 & 3.8 & 35 & 29 & 39 & \\
\hline No & 37 & 33.8 & 3.4 & 35 & 26 & 40 & \\
\hline
\end{tabular}

Notes: ${ }^{\mathrm{a} T w o-s a m p l e ~ t-t e s t ; ~}{ }^{\mathrm{b}}$ Wilcoxon-Mann-Whitney test.

Table 4 Percentage of each group divided by clinical classification of olfactory deficit

\begin{tabular}{|c|c|c|c|c|}
\hline Degree of olfactory loss & Normosmia & Mild microsmia & Moderate microsmia & $p$-value \\
\hline \multicolumn{4}{|l|}{ Gender } & $0.21^{\mathrm{a}}$ \\
\hline Male & 70.0 & 10.0 & 20.0 & \\
\hline Female & 50.0 & 31.8 & 18.2 & \\
\hline \multicolumn{4}{|l|}{ Residency group } & $0.18^{a}$ \\
\hline Otorhinolaryngology residents & 66.7 & 23.8 & 9.5 & \\
\hline Other residents & 52.4 & 19.0 & 28.6 & \\
\hline \multicolumn{4}{|l|}{ Year of residency } & $0.51^{\mathrm{a}}$ \\
\hline R1 & 50.0 & 33.3 & 16.7 & \\
\hline R2 & 53.8 & 23.1 & 23.1 & \\
\hline R3 & 80.0 & - & 20.0 & \\
\hline R4 & 100.0 & - & - & \\
\hline
\end{tabular}

Note: ${ }^{a}$ Chi-squared test.

age: 30 years), which used the same translated version of the test, the investigators observed a mean score of 35 points. This mean score was higher than the one observed in the present study, suggesting that residents of health programs had a worse sense of smell than the general population. Work-related factors impacting the lives of the residents, such as depression and excessive workload, may influence the well-being of these individuals, ${ }^{19}$ and could be related to lower UPSIT scores. ${ }^{20,21}$ Sleep deprivation also affects the activity of the insula and piriform cortex, a brain region responsible for odor processing. ${ }^{22}$ Moreover, the greater olfactory capacity observed in senior residents in 
comparison with first-year residents can be explained by the odor learning process that has been confirmed in multiple psychosocial studies ${ }^{4}$ and has served as a foundational tent for clinical olfactory training as we know today. ${ }^{4}$

In the sample of the present study, half of the female participants and half of the students in the first year of residency presented with olfactory dysfunction. The differences observed may also be due to the fact that menstrual cycles are associated with higher levels of stress among first-year residents. ${ }^{19}$ Instead of findings such as the one demonstrating that brain activation was consistently lower in females than in males, using functional magnetic resonance imaging, ${ }^{22}$ we still have more questions than answers regarding this complex understanding of the functional properties of the human olfactory system and neuroendocrine factors. ${ }^{23}$

Fornazieri et al. ${ }^{18}$ showed that socioeconomic status and schooling influence olfactory performance. Unfortunately, we were unable to confirm this hypothesis, because our sample consisted only of subjects with high socioeconomic status and level of schooling. We aimed for a sufficiently large sample size to be able to generalize our results to the general population of residents. Our sample size can be externally validated, especially when compared with the UPSIT cultural adaptation study performed by Fornazieri et al. ${ }^{18}$ with 49 participants.

\section{Conclusion}

The present study demonstrated that otorhinolaryngology residents have greater olfactory capacity compared with other residents. Future studies should explore the relevant factors of olfactory impairment and their impact on the quality of life of this population.

\section{Conflict of Interests}

The authors have no conflict of interests to declare.

\section{Acknowledgements}

The authors would like to thank the Otolaryngologist residents Shaadyla $\mathrm{R}$ Said and Aline Almeida Liberato for their contribution in some data collection.

\section{References}

1 Fitzgerald FT, Tierney LM Jr. The bedside Sherlock Holmes. West J Med 1982;137(02):169-175

2 Nagappan PG, Subramaniam S, Wang DY. Olfaction as a soldier- a review of the physiology and its present and future use in the military. Mil Med Res 2017;4:9

3 Smith DV. Assessment of patients with taste and smell disorders. Acta Otolaryngol Suppl 1988;458:129-133

4 Turner JH. Olfactory training: what is the evidence? [published online ahead of print, 2020 Aug 10]Int Forum Allergy Rhinol 2020. Doi: 10.1002/alr.22681
5 Brämerson A, Johansson L, Ek L, Nordin S, Bende M. Prevalence of olfactory dysfunction: the skövde population-based study. Laryngoscope 2004;114(04):733-737

6 Sugiura M, Aiba T, Mori J, Nakai Y. An epidemiological study of postviral olfactory disorder. Acta Otolaryngol Suppl 1998;538:191-196

7 Haxel BR, Nisius A, Fruth K, Mann WJ, Muttray A. [Deficits in medical counseling in olfactory dysfunction]. HNO 2012;60(05): 432-438

8 Doty RL, Shaman P, Dann M. Development of the University of Pennsylvania Smell Identification Test: a standardized microencapsulated test of olfactory function. Physiol Behav 1984;32 (03):489-502

9 Fornazieri MA, Doty RL, Santos CA, Pinna FdeR, Bezerra TF, Voegels RL. A new cultural adaptation of the University of Pennsylvania Smell Identification Test. Clinics (São Paulo) 2013; 68(01):65-68

10 Vandenbroucke JP, von Elm E, Altman DGSTROBE Initiative., et al; . Strengthening the Reporting of Observational Studies in Epidemiology (STROBE): explanation and elaboration. Int J Surg 2014; 12(12):1500-1524

11 Kaper NM, Aarts MCJ, van Benthem PPG, van der Heijden GJMG. Otolaryngologists adhere to evidence-based guidelines for chronic rhinosinusitis. Eur Arch Otorhinolaryngol 2019;276(04):1101-1108

12 Fowler J, Chin CJ, Massoud E. Rhinitis medicamentosa: a nationwide survey of Canadian otolaryngologists. J Otolaryngol Head Neck Surg 2019;48(01):70

13 Rezende GL, Granjeiro RC, Furtado PL, Pinheiro GB, Nakanishi M. Is dry climate related to hospital admission for epistaxis? Int Arch Otorhinolaryngol 2009;13:172-177

14 Croijmans I, Majid A. Not All Flavor Expertise Is Equal: The Language of Wine and Coffee Experts. PLoS One 2016;11(06): e0155845

15 Deems DA, Doty RL, Settle RG, et al. Smell and taste disorders, a study of 750 patients from the University of Pennsylvania Smell and Taste Center. Arch Otolaryngol Head Neck Surg 1991;117 (05):519-528

16 Doty RL. Olfactory dysfunction and its measurement in the clinic and workplace. Int Arch Occup Environ Health 2006;79(04): 268-282

17 Wang X, Zhang C, Xia X, Yang Y, Zhou C. Effect of gender on odor identification at different life stages: a meta-analysis. Rhinology 2019;57(05):322-330

18 Fornazieri MA, Doty RL, Bezerra TFP, et al. Relationship of socioeconomic status to olfactory function. Physiol Behav 2019; 198:84-89

19 Rezende GL, Mello MS, Granjeiro RC, Nakanishi M, Oliveira CA. The quality of life among Otorhinolaryngology residents in Distrito Federal (Brazil). Braz J Otorhinolaryngol 2011;77(04):466-472

20 Hur K, Choi JS, Zheng M, Shen J, Wrobel B. Association of alterations in smell and taste with depression in older adults. Laryngoscope Investig Otolaryngol 2018;3(02):94-99

21 Kohli P, Soler ZM, Nguyen SA, Muus JS, Schlosser RJ. The Association Between Olfaction and Depression: A Systematic Review. Chem Senses 2016;41(06):479-486

22 Bhutani S, Howard JD, Reynolds R, Zee PC, Gottfried J, Kahnt T. Olfactory connectivity mediates sleep-dependent food choices in humans. eLife 2019;8:e49053

23 Doty RL, Cameron EL. Sex differences and reproductive hormone influences on human odor perception. Physiol Behav 2009;97 (02):213-228 